Research Article

\title{
Long Noncoding RNA GATA3-AS1 Promotes Cell Proliferation and Metastasis in Hepatocellular Carcinoma by Suppression of PTEN, CDKN1A, and TP53
}

\author{
Xuee Luo $\mathbb{D}^{D}$, Ning Zhou $\left(\mathbb{D}\right.$, Le Wang $\left(\mathbb{D}\right.$, Qinghua Zeng $\mathbb{D}^{(D)}$, and Hongying Tang $(\mathbb{D}$ \\ Laboratory of Hepatobiliary Molecular Oncology, Department of Hepatopancreatobiliary Surgery, \\ Hunan Provincial People's Hospital, The First Affiliated Hospital of Hunan Normal University, Changsha 410011, \\ Hunan Province, China \\ Correspondence should be addressed to Ning Zhou; zhouning_198401@126.com and Hongying Tang; \\ tanghylady79@aliyun.com
}

Received 30 July 2019; Accepted 31 October 2019; Published 2 December 2019

Academic Editor: José L. Mauriz

Copyright (c) 2019 Xuee Luo et al. This is an open access article distributed under the Creative Commons Attribution License, which permits unrestricted use, distribution, and reproduction in any medium, provided the original work is properly cited.

\begin{abstract}
Background. Long noncoding RNAs (lncRNAs) have been known to play important roles in the progression of various types of human cancer. LncRNA GATA3 antisense RNA 1, GATA3-AS1, has been reported to be associated with T-cell development and differentiation. However, the expression pattern and function of GATA3-AS1 in hepatocellular carcinoma (HCC) remain unknown. Methods. Real-time quantitative PCR (RT-qPCR) assay was conducted to detect GATA3-AS1 expression levels in 80 cases of pairs HCC tissues and matched normal tissues. Chi-squared $\left(\chi^{2}\right)$ test was used to analyze the correlation between GATA3AS1 expression and clinicopathologic variables. Survival curves were plotted using the Kaplan-Meier method and were compared via the log-rank test. The cell counting kit-8 (CCK-8) and wound scratch assays were applied to detect the effect of GATA3-AS1 knockdown and overexpression on cell growth and migration of HCC. RT-qPCR was performed for the detection of the phosphatase and tensin homolog (PTEN), cyclin-dependent kinase inhibitor 1A (CDKN1A), and tumor protein p53 (TP53) expression in HCC cells after GATA3-AS1 knockdown and overexpression. Results. GATA3-AS1 was significantly upregulated in HCC tissues compared with matched normal tissues. The high expression of GATA3-AS1 was significantly correlated with larger tumor size, advanced TNM stage, and more lymph node metastasis. High GATA3-AS1 expression was markedly correlated with shorter overall survival times of HCC patients. Furthermore, knockdown of GATA3-AS1 obviously inhibited Hep3B and HCCLM3 cell growth and migration, whereas overexpression of GATA3-AS1 had the opposite effects. In addition, GATA3-AS1 knockdown resulted in upregulated expression levels of tumor-suppressive genes, PTEN, CDKN1A, and TP53, in Hep3B and HCCLM3 cells, while restoration of GATA3-AS1 decreased PTEN, CDKN1A, and TP53 expression levels. Conclusion. Our data suggested that GATA3-AS1 promotes cell proliferation and metastasis of HCC by suppression of PTEN, CDKN1A, and TP53.
\end{abstract}

\section{Introduction}

Hepatocellular carcinoma (HCC) is one of the most common diagnosed malignancies and the second leading cause of tumor-related deaths worldwide [1]. According to the global cancer statistics, approximately 500,000 new cases and 600,000 cases of mortalities occur every year [2]. The longterm prognosis of HCC remains very poor, with a low 5overall survival rate of $35 \%$ [3]. Surgical removal of the tumor and liver transplant are currently the most applicable options for HCC; however, tumor metastasis and recurrence are extremely common in postoperative HCC patients $[4,5]$. At present, because of the poor understanding of pathological molecular mechanisms in HCC, the effective therapy for this cancer is very limited [6]. Therefore, it is essential to identify the mechanisms that underlie HCC metastasis for the development of novel sensitive and effective therapies.

Long noncoding RNAs (lncRNAs) are a class of noncoding RNAs which surpass 200 nucleotides in length [7]. According to the chromosome region to their adjacent 
coding genes, lncRNAs can be divided into five categories, including sense, antisense, bidirectional, intronic, and intergenic lncRNAs [8]. Accumulating data demonstrated that lncRNAs play vital roles in various biological processes, such as cell growth and differentiation, immune activation/ inactivation, and transcriptional and posttranscriptional regulation [9]. Recent studies have identified that some of lncRNAs were closely participated in tumorigenesis and metastasis and can be used as the effective biomarkers for HCC $[10,11]$. Therefore, more and more researchers are keen on the eyes of lncRNAs in the progression of HCC.

In recent years, antisense lncRNAs have been identified to regulate cell proliferation, migration, and invasion in cancer [12]. For example, lncRNA antisense transcript of coding gene PCNA, PCNA-AS1, is shown to increase HCC cell growth [13]. The lncRNA MDC1 antisense RNA 1 (MDC1-AS1) associates with the development of bladder cancer [14]. The lncRNA AFAP1 antisense RNA 1, AFAP1AS1, plays an oncogenic role in promoting cell migration in non-small cell lung cancer [15]. Besides, lncRNA DLX6 antisense RNA 1 (DLX6-AS1) promotes malignant phenotypes of gastric cancer cells [16]. The GATA3 antisense RNA 1 (GATA3-AS1) is a new antisense lncRNA, which is associated with T-cell development and differentiation [17]. It was later confirmed that GATA3-AS1 regulates GATA3 transcription in T-helper 2 cells [18]. However, the expression levels and function of GATA3-AS1 in HCC remain unknown. In this study, we firstly determined GATA3-AS1 expression in HCC tissues and cells. Then, we performed in vitro loss- and gain-of-function experiments for GATA3AS1 in the progression of HCC. This study highlighted the oncogenic role of GATA3-AS1 in regulating HCC cell proliferation and metastasis.

\section{Materials and Methods}

2.1. HCC Specimens. Human HCC tissue and matched normal tissues were randomly collected from Department of Hepatopancreatobiliary Surgery, Hunan Provincial People's Hospital (Changsha, China) between June 2006 and December 2015. A total of 80 cases of HCC were enrolled in the study. All tissues were instantly frozen in liquid nitrogen after operation until use. This research was approved by the Institutional Review Board of Hunan Provincial People's Hospital (no. 2017064). The written informed consent was obtained from all patients or their relatives based on the Declaration of Helsinki. The HCC stage was classified according to the modified tumor-node-metastasis (TNM) cancer staging system published by the International Union Against Cancer (UICC, 2009) [19]. The clinicopathological information is summarized in Table 1.

2.2. Cell Culture. Two human HCC cells (Hep3B and HCCLM3) and the normal liver cell line (HL-7702) were obtained from the Shanghai Institute of Biochemistry and Cell Biology, Chinese Academy of Sciences (Shanghai, China). The Hep3, HCCLM3, and HL-7702 cells were maintained in the RPMI 1640 medium (Invitrogen,
Carlsbad, CA, USA) plus 10\% FBS (Invitrogen, Carlsbad, CA, USA) with $100 \mathrm{U} / \mathrm{ml}$ penicillin and $100 \mu \mathrm{g} / \mathrm{ml}$ streptomycin at $37^{\circ} \mathrm{C}$ with $5 \% \mathrm{CO}_{2}$.

2.3. Transfection. To knockdown an endogenous GATA3AS1 expression, GATA3-AS1 small interfering RNA (siRNA) (sequence: $5^{\prime}$-UCUCCGCGCGUCAAUCGA-3') and control siRNA (sequence: $5^{\prime}$-CUACACCGUAUUCUACUACUA-3') were obtained from Genechem Co., Ltd. (Shanghai, China). To overexpress GATA3-AS1, pcDNA 3.1 + GATA3-AS1 recombinant plasmid was constructed by inserting an EcoRI-Xhol fragment containing the GATA3AS1 transcript into the same sites in pcDNA3.1 + vector. The pcDNA3.1 + vector (empty vector) was used as a negative control for pcDNA3.1 + GATA3-AS1 plasmid. The total GATA3-AS1 transcript was amplified from HCCLM3 cells by RT-PCR using the specific primers: $5^{\prime}$-GCTGCAGCCGCTGGCCCGAAAATGC-3' (sense) and 5' -TTCTAAAGGTGGGGGTTGCCCTTCT-3' (antisense). The primers were bought from Life Technologies (Invitrogen, Carlsbad, CA, USA), and the sequences of recombinant plasmid were confirmed in Life Technologies (Invitrogen) by Sanger DNA sequencing. For cell transfection, Hep3B and HCCLM3 cells were transfected with 200 pmol GATA3-AS1 siRNA/control siRNA or $4 \mu \mathrm{g}$ pcDNA3.1 + GATA3-AS1 vector/empty vector by using Lipofectamine 2000 transfection reagent (Invitrogen) according to the instructions. The cells were collected, and transfection efficiency was examined using real-time quantitative PCR (RT-qPCR) assay after $48 \mathrm{~h}$ transfection.

2.4. RT-qPCR. Total RNA was extracted from HCC tissues and cells using TRIzol reagent (Invitrogen, Carlsbad, CA, USA) according to the manufacturer's instructions. The eligible RNA (OD 260/280 at 1.8-2.0) was converted to cDNA using the M-MLV Reverse Transcriptase kit (Toyobo, Osaka, Japan). After that, qPCR was carried out using a SYBR_Premix ExTaq II kit (Toyobo) on Applied Biosystems 7500 Real-Time PCR system (Applied Biosystems, Foster City, CA) to quantify the relative expression of target genes. The specific primers used for the amplification were shown in Table 2. ACTB (actin beta) was used as the internal control. The average of three independent data for each gene was calculated using $2^{-\Delta \Delta C q}$ method [20].

2.5. Cell Proliferation Assay. The proliferation ability of HCC cells was detected using the cell counting kit-8 (CCK-8) assay (Dojindo Laboratories, Kumamoto, Japan). About 6000 cells of Hep3B and HCCLM3 were plated in 96-well plates per well and cultured in the RPMI 1640 medium for $24 \mathrm{~h}$. Then, cells were treated with $50 \mathrm{pmol}$ GATA3-AS1 siRNA/control siRNA or $0.5 \mu \mathrm{g}$ pcDNA3.1 + GATA3-AS1 vector/empty vector using lipofectamine 2000 transfection reagent, according to the manufacturer's instructions. $10 \mu \mathrm{l}$ CCK- 8 solution/well was added, and cell proliferation ability was determined $0,24,48$, and $72 \mathrm{~h}$ after transfection. The numbers of proliferative cells per well were measured at the 
TABLE 1: The correlations between lncRNA GATA3-AS1 expression and clinicopathologic variables in patients with hepatocellular carcinoma.

\begin{tabular}{|c|c|c|c|c|c|}
\hline \multirow{2}{*}{ Variables } & \multirow{2}{*}{ Cases } & \multicolumn{2}{|c|}{ GATA3-AS1 } & \multirow{2}{*}{$\chi^{2}$} & \multirow{2}{*}{$P$} \\
\hline & & Low & High & & \\
\hline \multicolumn{6}{|l|}{ Gender } \\
\hline Male & 51 & 19 & 32 & \multirow[b]{2}{*}{0.442} & \multirow{2}{*}{0.506} \\
\hline Female & 29 & 13 & 16 & & \\
\hline \multicolumn{6}{|l|}{ Age (years) } \\
\hline$<55$ & 35 & 17 & 18 & \multirow{2}{*}{1.905} & \multirow{2}{*}{0.168} \\
\hline$\geq 55$ & 45 & 15 & 30 & & \\
\hline \multicolumn{6}{|c|}{ Tumor size $(\mathrm{cm})$} \\
\hline$<5$ & 26 & 16 & 10 & \multirow[b]{2}{*}{7.445} & \multirow[b]{2}{*}{$0.006^{*}$} \\
\hline$\geq 5$ & 54 & 16 & 38 & & \\
\hline \multicolumn{6}{|c|}{ Differentiation } \\
\hline Low & 46 & 17 & 29 & \multirow{3}{*}{1.838} & \multirow{3}{*}{0.372} \\
\hline Moderate & 29 & 14 & 15 & & \\
\hline High & 5 & 1 & 4 & & \\
\hline \multicolumn{6}{|c|}{ Liver cirrhosis } \\
\hline No & 23 & 9 & 14 & \multirow{2}{*}{0.010} & \multirow{2}{*}{0.920} \\
\hline Yes & 57 & 23 & 34 & & \\
\hline \multicolumn{6}{|c|}{ Lymph node metastasis } \\
\hline No & 41 & 25 & 16 & \multirow{2}{*}{14.626} & \multirow{2}{*}{$<0.001^{*}$} \\
\hline Yes & 39 & 7 & 32 & & \\
\hline \multicolumn{6}{|c|}{ Venous invasion } \\
\hline No & 18 & 10 & 8 & \multirow{2}{*}{2.342} & \multirow{2}{*}{0.126} \\
\hline Yes & 62 & 22 & 40 & & \\
\hline \multicolumn{6}{|l|}{ TNM stage } \\
\hline $\mathrm{I}+\mathrm{II}$ & 27 & 17 & 10 & \multirow[b]{2}{*}{8.954} & \multirow{2}{*}{$0.003^{*}$} \\
\hline III + IV & 53 & 15 & 38 & & \\
\hline
\end{tabular}

LncRNA: long noncoding RNA, GATA3-AS1: GATA3 antisense RNA $1 .{ }^{*} P<0.05$.

TABLe 2: The specific primer sequences for RT-qPCR.

\begin{tabular}{lcc}
\hline Gene & Sense $\left(5^{\prime}-3^{\prime}\right)$ & Antisense $\left(5^{\prime}-3^{\prime}\right)$ \\
\hline GATA3-AS1 & TTGTTCCCTCTTCGCTCCT & TTGTTCCTTCACCGCATG \\
PTEN & ACCATAACCCACCACAGC & CAGTTCGTCCCTTTCCAG \\
CDKN1A & TCTACATCTTCTGCCTTAG & AAATGCCCAGCACTCTTA \\
TP53 & TAAGGGTTAGTTTACAATC & TGCCAGCATTTCACAGAT \\
ACTB & ACTTAGTTGCGTTACACC & GTCACCTTCACCGTTCCA \\
\hline
\end{tabular}

RT-qPCR: real-time quantitative PCR, PTEN: phosphatase and tensin homolog, CDKN1A: cyclin-dependent kinase inhibitor 1A, TP53: tumor protein p53, and ACTB: actin beta.

absorbance $(480 \mathrm{~nm})$ by using a microplate reader (Bio-Rad, Hercules, CA, USA) at the indicated time points.

2.6. Wound Scratch Assay. Wound scratch assay was used to evaluate the metastatic ability of Hep3B and HCCLM3 cell lines in vitro. Approximately $8 \times 10^{6}$ cells were seeded into per 6-well plates and transfected with 200 pmol GATA3-AS1 siRNA/control siRNA or $4 \mu \mathrm{g}$ pcDNA3.1 + GATA3-AS1 vector/empty vector. After $6 \mathrm{~h}$ transfection, the cell monolayer was scraped using a yellow pipette tip. The beginning gap length at $0 \mathrm{~h}$ and the residual gap length at $12 \mathrm{~h}$ were detected using the Image Analysis and Detection System (MIAS) (Leica Microsystems GmbH, Wetzlar, Germany). The experiments were conducted in triplicate and repeated at least three times and then analyzed by at least two observers with a double-blind manner.
2.7. Statistical Analysis. Data were presented as mean \pm SD (standard deviation) of three independent experiments. The statistical analyses were performed using SPSS 17.0 (SPSS Inc., Chicago, IL, USA). The expression differences between HCC tissues and matched normal tissues were analyzed using paired student's $t$-test. Chi-squared $\left(\chi^{2}\right)$ test was used for correlation analysis. Survival curves were plotted using the Kaplan-Meier method and were compared via the logrank test. CCK-8 assay was analyzed using one way-ANOVA following Bonferroni's post hoc test. The value of $P<0.05$ was considered to be a statistically significant difference.

\section{Results}

3.1. The GATA3-AS1 Expression Levels Are Markedly Upregulated in HCC Tissues and Cell Lines. In order to identify the 
clinical significance of GATA3-AS1 in HCC patients, we firstly determined the GATA3-AS1 expression in HCC specimens. As shown in Figure 1(a), the GATA3-AS1 expression was significantly upregulated in HCC tissues compared with matched normal tissues $(P<0.05)$. We then analyzed the expression levels of GATA3-AS1 in two human HCC cells (Hep3B and HCCLM3) and the normal liver cell line (HL-7702). Consistent with the data of HCC specimens, GATA3-AS1 expression was obviously increased in the Hep3B and HCCLM3 cells compared with the HL-7702 cells (Figure 1(b), $P<0.05$ ). The results indicated that upregulation of GATA3-AS1 may associate with the progression of HCC.

\subsection{Upregulation of GATA3-AS1 Is Associated with the Ag-} gressive Phenotypes and Poor Prognosis in HCC Patients. The 80 pairs of HCC cases were divided into two groups based on the mean value of relative GATA3-AS1 expression levels, including low $(n=32)$ and high $(n=48)$ GATA3-AS1 expression groups. The $\chi^{2}$ test was used to analyze the correlation between GATA3-AS1 expression and clinicopathologic variables. As shown in Table 1, the high level of GATA3-AS1 expression was strongly correlated with larger tumor size $(P=0.006)$, advanced TNM stage $(P=0.003)$, and more lymph node metastasis $(P<0.001)$ but not correlated with patient's gender $(P=0.506)$, age $(P=0.168)$, differentiation $(P=0.372)$, vascular invasion $(P=0.126)$, and liver cirrhosis $(P=0.920)$. Furthermore, Kaplan-Meier survival analysis showed a clear negative correlation between GATA3-AS1 expression and overall survival of HCC patients (Figure 2). The patients with high levels of GATA3AS1 expression had a significantly shorter overall survival times compared with those with low GATA3-AS1 expression $(P<0.001)$. These results indicated that high expression of GATA3-AS1 is associated with the aggressive phenotypes and poor prognosis of HCC patients.

\subsection{GATA3-AS1 Promotes Cell Proliferation in Hep3B and} HCCLM3 Cells. To examine the biological function of GATA3-AS1 in regulating HCC cell proliferation, Hep3B and HCCLM3 cells transfected with GATA3-AS1 siRNA/ control siRNA or pcDNA3.1 + GATA3-AS1 vector/empty vector were analyzed using CCK-8 assay. GATA3-AS1 siRNA significantly decreased GATA3-AS1 expression levels in Hep3B and HCCLM3 cell lines (Figures 3(a) and 3(b), $P<0.05)$. GATA3-AS1 knockdown obviously inhibited cell proliferation in Hep3B and HCCLM3 cells (Figures 3(c) and 3(d), $P<0.05)$. Oppositely, pcDNA3.1 + GATA3-AS1 vector markedly increased GATA3-AS1 expression in Hep3B and HCCLM3 cell lines (Figures $4(\mathrm{a})$ and $4(\mathrm{~b}), P<0.05$ ). GATA3-AS1 overexpression notably promoted cell proliferation in Hep3B and HCCLM3 cells (Figures 4(c) and $4(\mathrm{~d}), P<0.05)$. These data demonstrated that GATA3-AS1 contributes to cell proliferation in HCC.

3.4. GATA3-AS1 Facilitates Cell Metastasis in Hep3B and HCCLM3 Cells. Wound scratch assay was used to evaluate metastatic ability in HCC cells. The distance of cell migration in Hep3B cells transfected with GATA3-AS1 siRNA was significantly shorter compared with cells treated with control siRNA (Figure 5(a), $P<0.05$ ). Similar results were found in HCCLM3 cells after transfection of GATA3-AS1 siRNA/ control siRNA (Figure 5(a), $P<0.05$ ). By contrast, Hep3B cells transfected with pcDNA3.1+GATA3-AS1 vector showed longer distance of cell migration compared with cells treated with empty vector (Figure 5(b), $P<0.05$ ). Similar results were also shown in HCCLM3 cells after transfection of pcDNA3.1 + GATA3-AS1 vector/empty vector (Figure 5(b), $P<0.05$ ). These data demonstrated that GATA3-AS1 promotes cell metastasis in HCC.

3.5. GATA3-AS1 Suppresses PTEN, CDKN1A, and TP53 Expression in HCC Cells. To investigate the molecular mechanisms underlying the GATA3-AS1-mediated increase in HCC cell proliferation and metastasis, the expression levels of tumor-suppressive genes that play inhibitory roles in HCC progression were evaluated by RT-qPCR, including phosphatase and tensin homolog (PTEN) [21], cyclin-dependent kinase inhibitor $1 \mathrm{~A}$ (CDKN1A) [22], and tumor protein p53 (TP53) [23]. As shown in Figures 6(a) and 6(b), GATA3-AS1 knockdown resulted in upregulation of PTEN, CDKN1A, and TP53 in Hep3B and HCCLM3 cells $(P<0.05)$, while restoration of GATA3-AS1 notably decreased PTEN, CDKN1A and TP53 expression (Figures 6(c) and $6(\mathrm{~d}), P<0.05)$. These data demonstrated that GATA3AS1 promotes cell proliferation and metastasis in HCC by suppression of PTEN, CDKN1A and TP53.

\section{Discussion}

Recent research studies suggested that mammalian transcriptome is more complex than protein-coding genes, and global transcriptome analysis provides detail evidences that a large proportion of human genome can generate transcripts from both strands [24]. More and more studies recently have demonstrated that lncRNAs participate in the regulation of cellular growth, metabolism, apoptosis, invasion, and metastasis [25]. For example, a liver-enriched lncRNA, liver-specific triglyceride regulator (LSTR), can regulate systemic lipid metabolism in mice [26]. Downregulation of lncRNA maternally expressed 3 (MEG3) has an effect on suppressing trophoblast cell migration and promoting apoptosis [27]. The lncRNA H19 imprinted maternally expressed transcript (H19) is significantly upregulated in hepatocellular carcinoma, and confers growth, migration, and invasion advantages on cancer cells [28]. Evidences have indicated that the antisense lncRNAs are participated in complicate pathophysiological processes of human diseases [29]. Thus, we hypothesized that antisense lncRNAs may play crucial roles in progression of HCC.

GATA3-AS1 is a newly antisense lncRNAs, which first identified from human CD4+ T-cell subsets [30]. Subsequently, Zhu et al. [31] applied microarray to analyze lncRNAs expression profiles in human bladder cancer and 


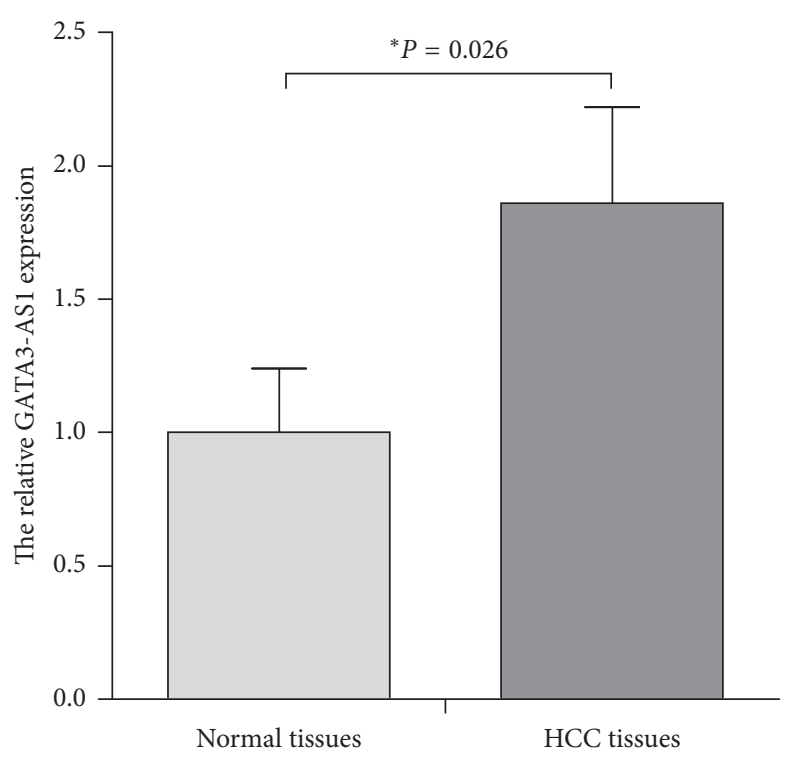

(a)

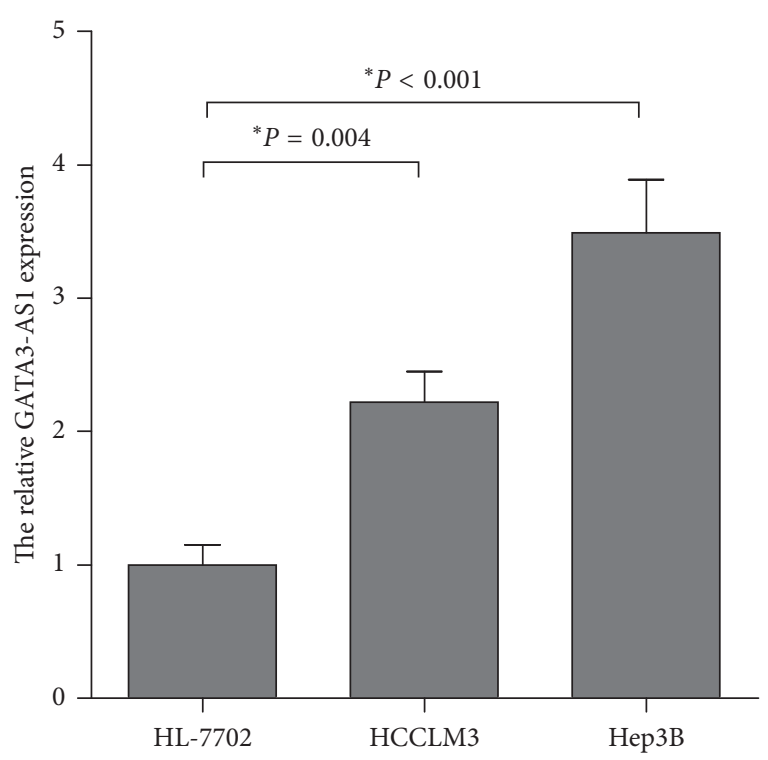

(b)

Figure 1: The lncRNA GATA3-AS1 expression levels are markedly upregulated in HCC tissues and cell lines. (a) GATA3-AS1 expression levels were examined in 80 cases of pairs HCC tissues and matched normal tissues using RT-qPCR analysis. The $2^{-\Delta \Delta C q}$ method was used to analyze the results, and ACTB was used as the internal control. (b) GATA3-AS1 expression levels were detected by RT-qPCR assay in the two human HCC cell lines (Hep3B and HCCLM3) and the normal liver cell line (HL-7702). LncRNA: long noncoding RNA, GATA3-AS1 : GATA3 antisense RNA 1, HCC: hepatocellular carcinoma, RT-qPCR: real-time quantitative PCR, and ACTB: actin beta. Data were expressed as the mean \pm SD $(n=3) ;{ }^{*} P<0.05$.

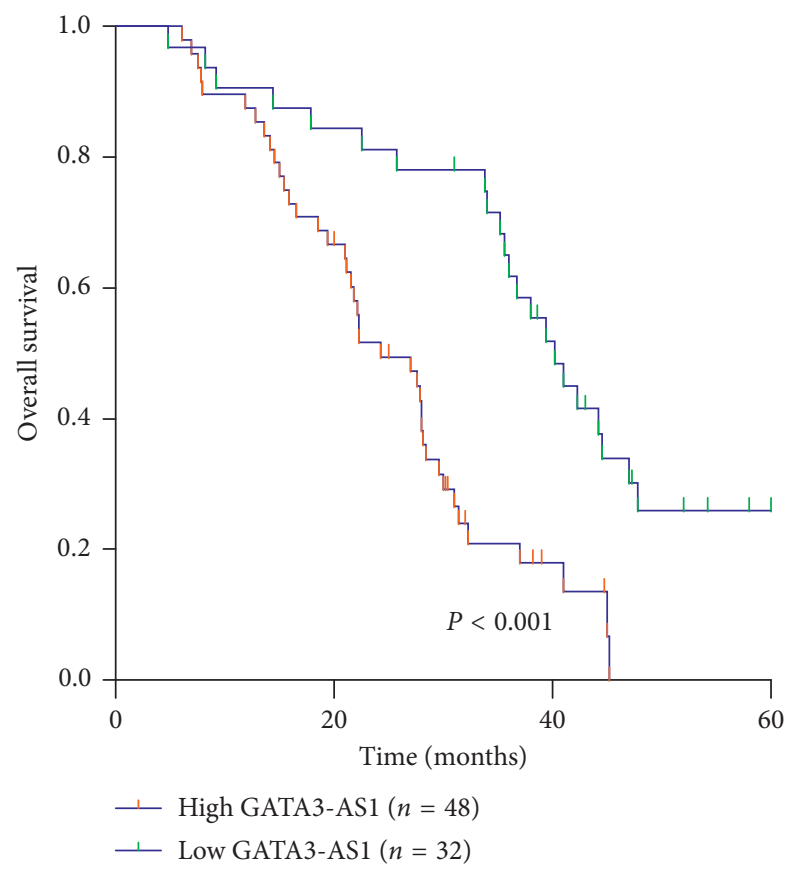

FIGURE 2: The association between GATA3-AS1 expression and prognosis of patients with HCC. Kaplan-Meier survival analysis and logrank test indicated that high GATA3-AS1 expression was markedly correlated with shorter overall survival times of HCC patients.

matched normal bladder tissues and found GATA3-AS1 is remarkably upregulated in tumor tissues. Recently, Gibbons et al. [18] demonstrated that GASTA3-AS1 significantly contributes to TH2 development. However, the expression pattern and role of GATA3-AS1 are largely unknown in
HCC until now. In this study, we identified that the GATA3AS1 expression is commonly upregulated in HCC tissues and Hep3B and HCCLM3 cells, indicating that GATA3-AS1 might have an important function in the progression of HCC. Besides, the elevated GATA3-AS1 expression was 


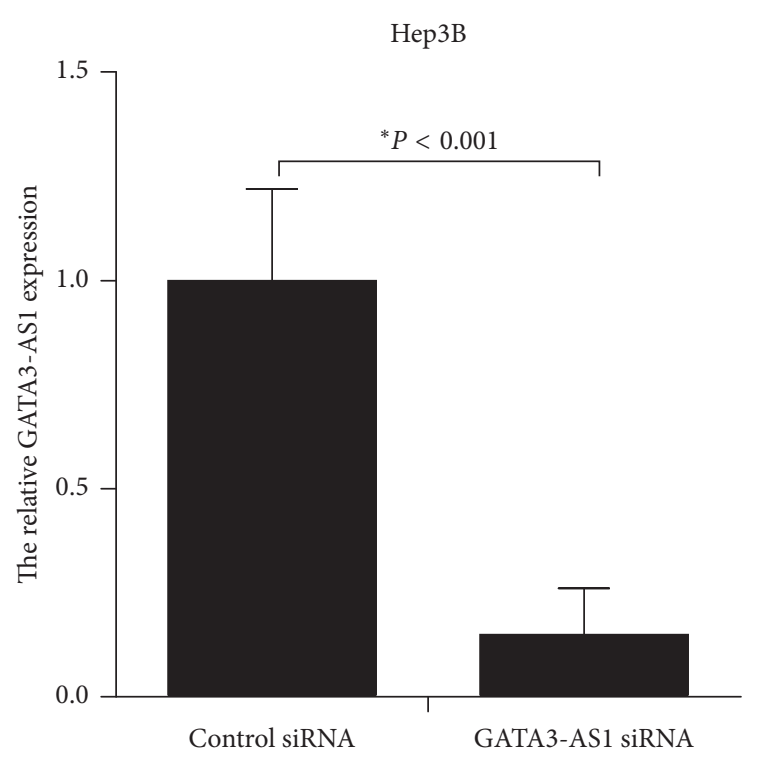

(a)

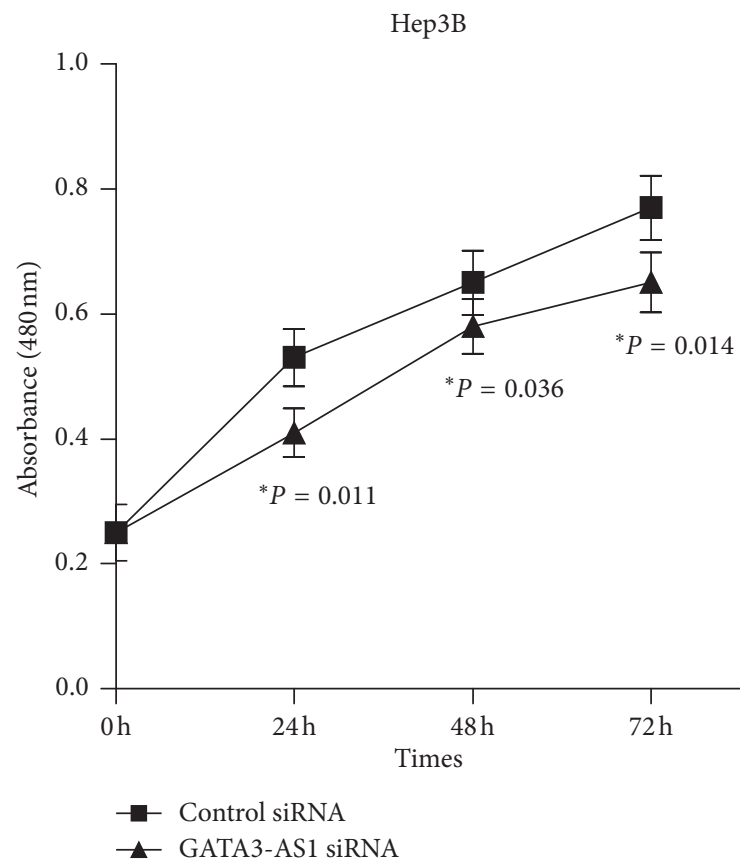

(c)

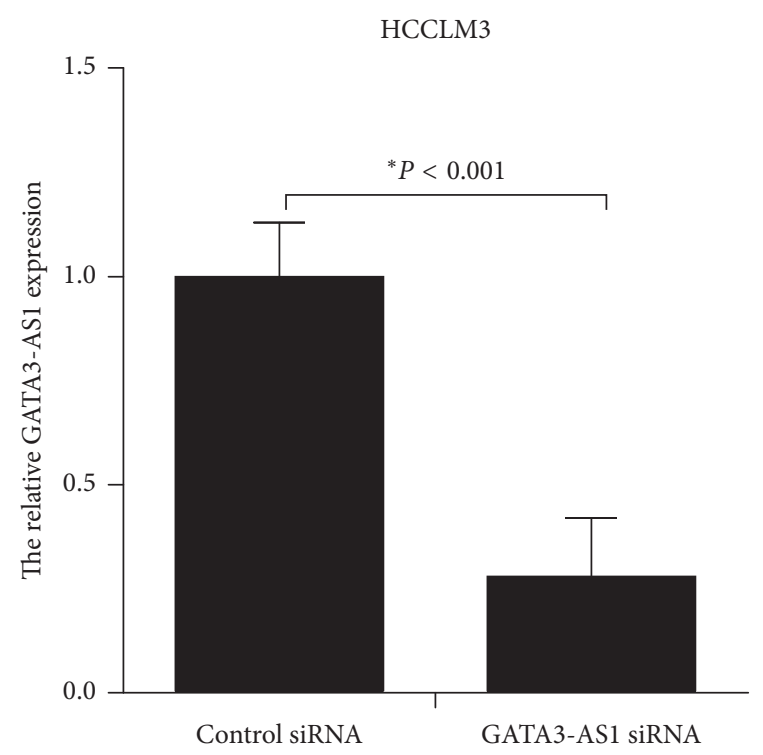

(b)

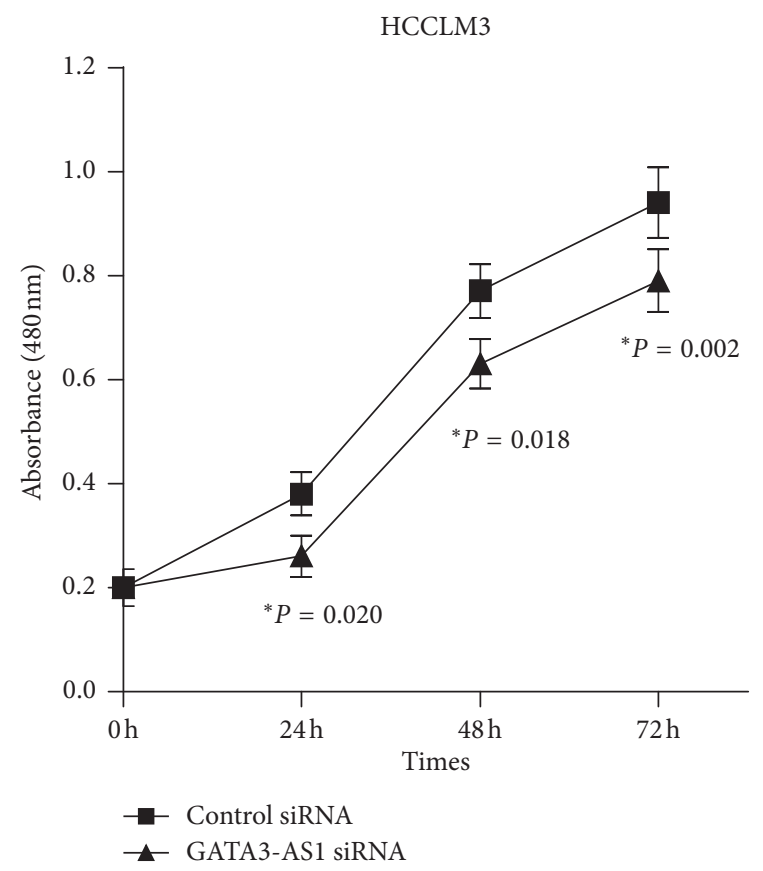

(d)

Figure 3: GATA3-AS1 knockdown inhibits cell proliferation in Hep3B and HCCLM3 cells. (a, b) Hep3B and HCCLM3 cells were transfected with GATA3-AS1 siRNA, and control siRNA was used as a negative control. GATA3-AS1 expression levels were analyzed after $48 \mathrm{~h}$ of transfection by RT-qPCR. (c) The CCK- 8 assay was performed to assess the growth ability of Hep3B cells after treated with GATA3AS1 siRNA/control siRNA. (d) GATA3-AS1 knockdown could inhibit cell proliferation in HCCLM3 cells. CCK-8: cell counting kit-8, siRNA: small interfering RNA. The results were showed as the mean \pm SD from at least three independent experiments; ${ }^{*} P<0.05$.

closely correlated with larger tumor size, advanced TNM stage, and more lymph node metastasis, suggesting that upregulation of GATA3-AS1 represented an aggressive phenotype of HCC. Subsequently, in vitro loss- and gain-offunction experiments revealed that overexpression of GATA3-AS1 contributed to HCC cell proliferation and metastasis, whereas knockdown of GATA3-AS1 inhibited cell growth and metastasis. These data strongly demonstrated that
GATA3-AS1 acts as an oncogenic role in the progression of HCC.

TP53 is known as a tumor suppressor gene in various types of human cancer, and low expression of TP53 is associated with tumor progression and poor prognosis of HCC $[32,33]$. PTEN is a plasma membrane lipid phosphatase, which is identified as a tumor suppressor gene in multiple types of neoplasm [34]. In recent years, numerous previous 


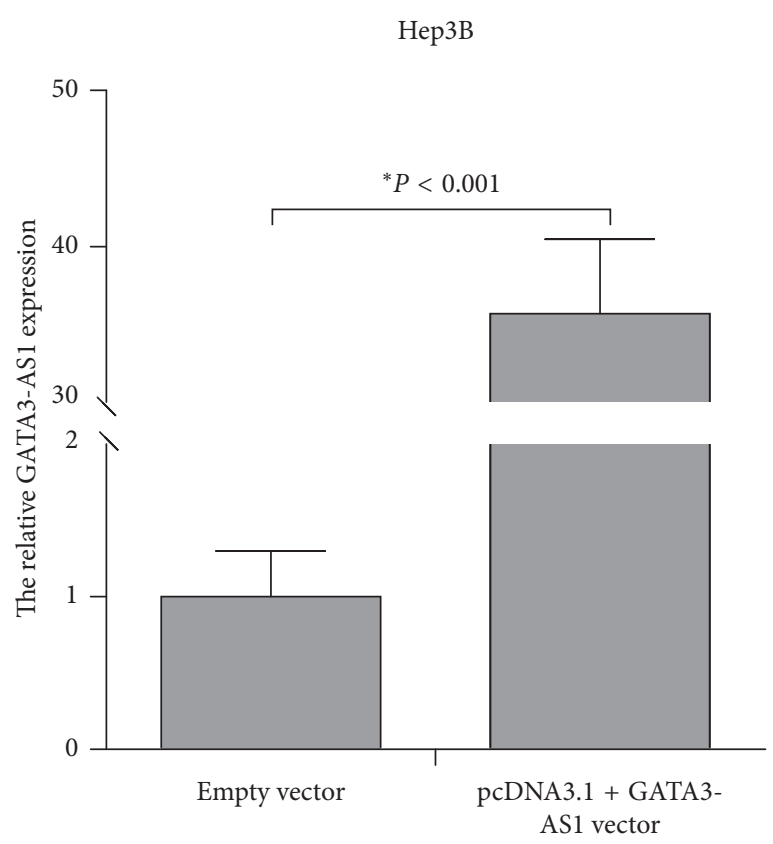

(a)

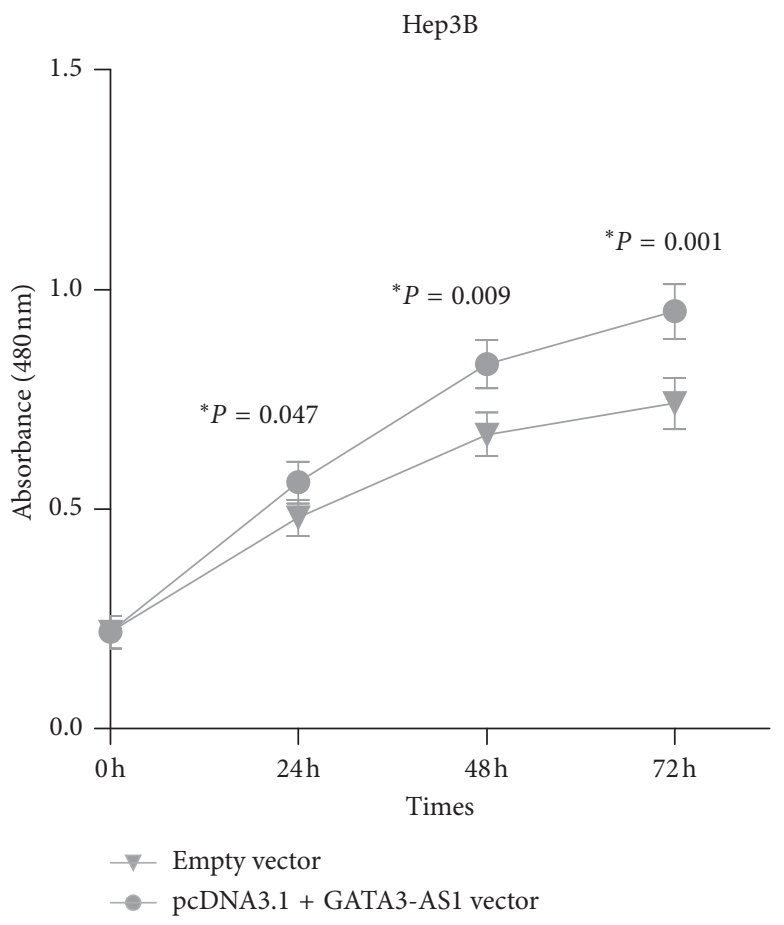

(c)

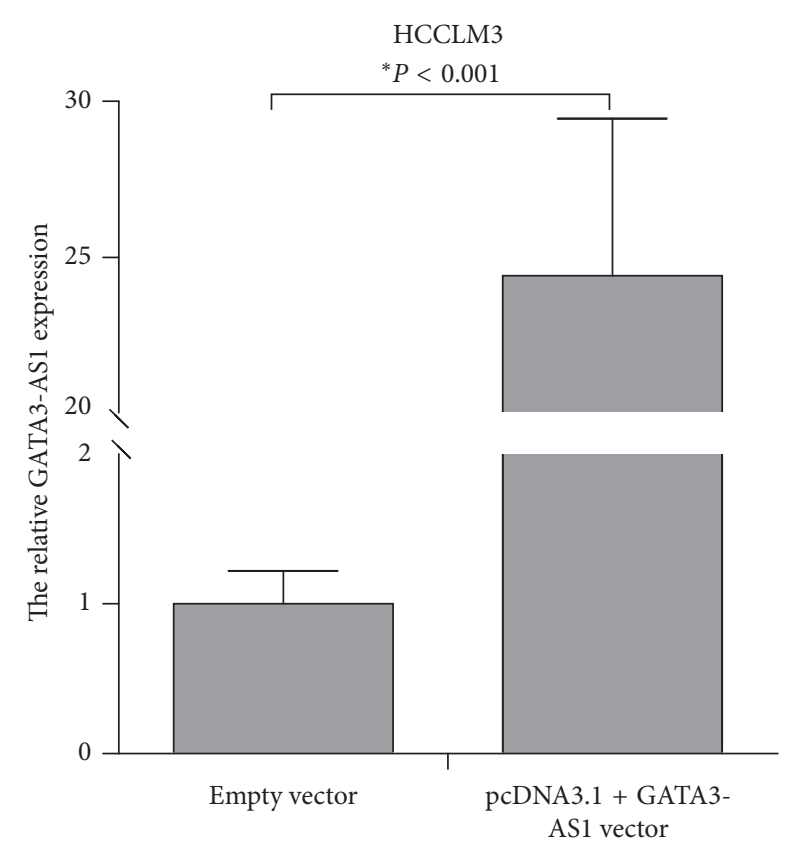

(b)

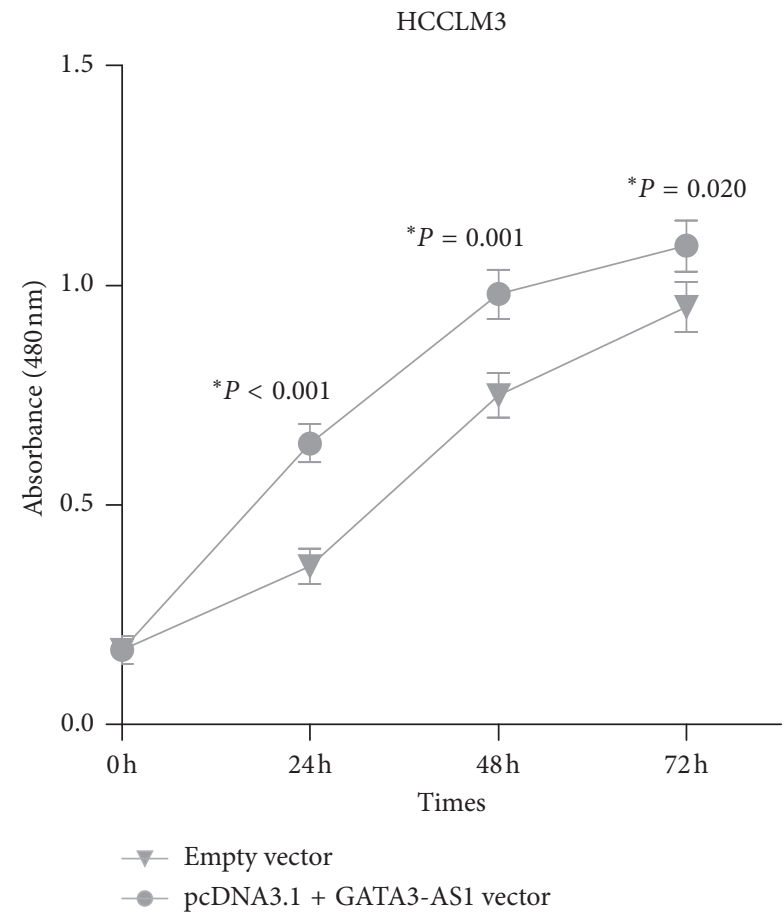

(d)

FIgURE 4: GATA3-AS1 overexpression promotes cell proliferation in Hep3B and HCCLM3 cells. (a, b) pcDNA3.1 + GATA3-AS1 vector markedly increased GATA3-AS1 expression in Hep3B and HCCLM3 cell lines. (c) The CCK-8 assay was performed to evaluate the growth ability of Hep3B cells after transfection of pcDNA3.1 + GATA3-AS1 vector/empty vector. (d) GATA3-AS1 overexpression promoted cell proliferation in HCCLM3 cells. The results were showed as the mean \pm SD from at least three independent experiments; ${ }^{*} P<0.05$.

studies have demonstrated that downregulated PTEN expression is associated with poor overall survival and carcinogenesis in HCC. CDKN1A is regarded as a key inhibitor of cell cycle, mediator of DNA damage, and effector of the TP53, displaying an important role in the progression of HCC [35]. To investigate the molecular mechanisms underlying the
GATA3-AS1-mediated increase in HCC cell proliferation and metastasis, the expression levels of TP53, PTEN, and CDKN1A were evaluated by RT-qPCR. The results showed that GATA3-AS1 inhibition significantly elevated PTEN, CDKN1A, and TP53 expression levels in HCC cells, while restoration of GATA3-AS1 decreased PTEN, CDKN1A, and 

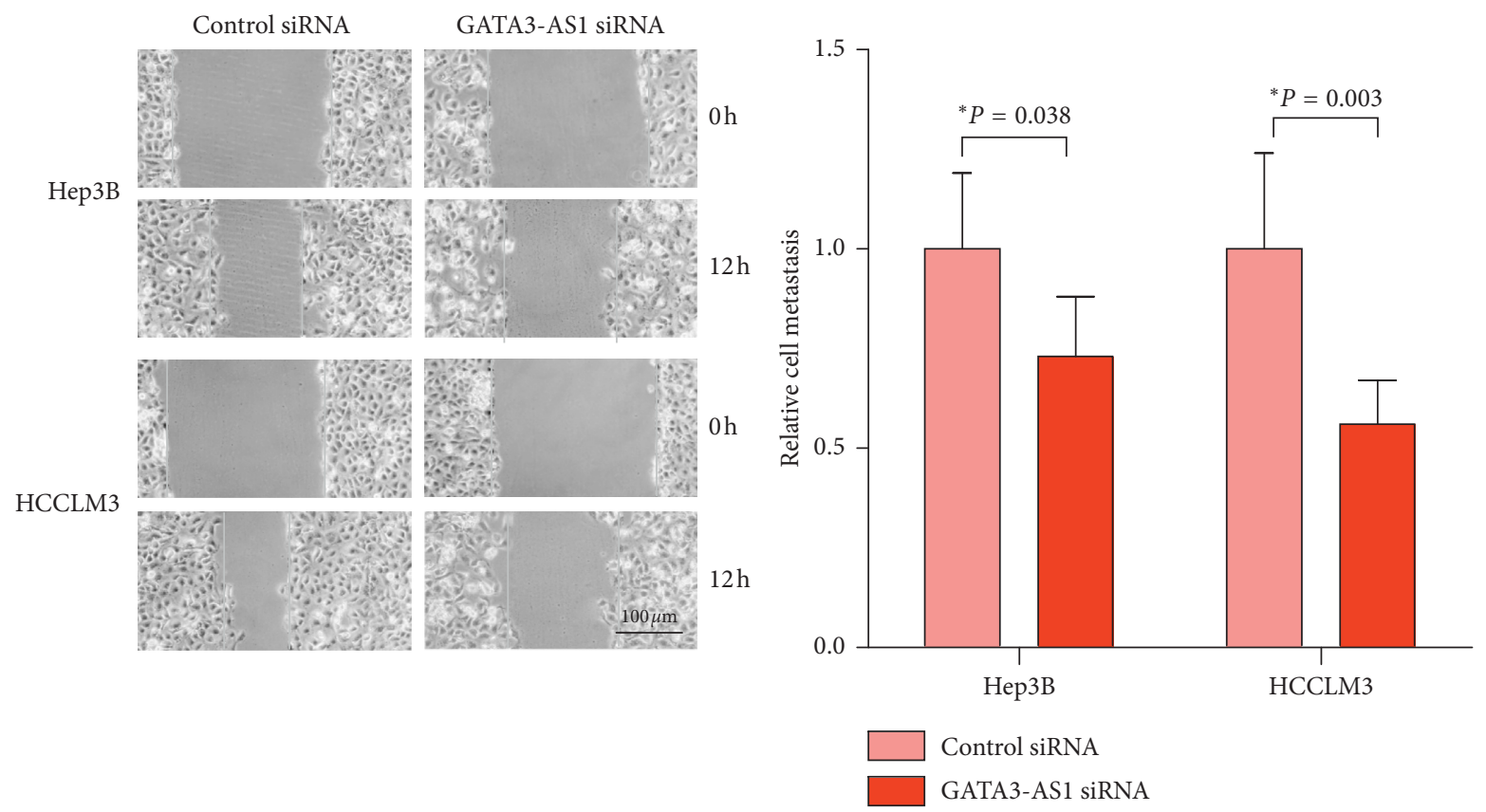

(a)
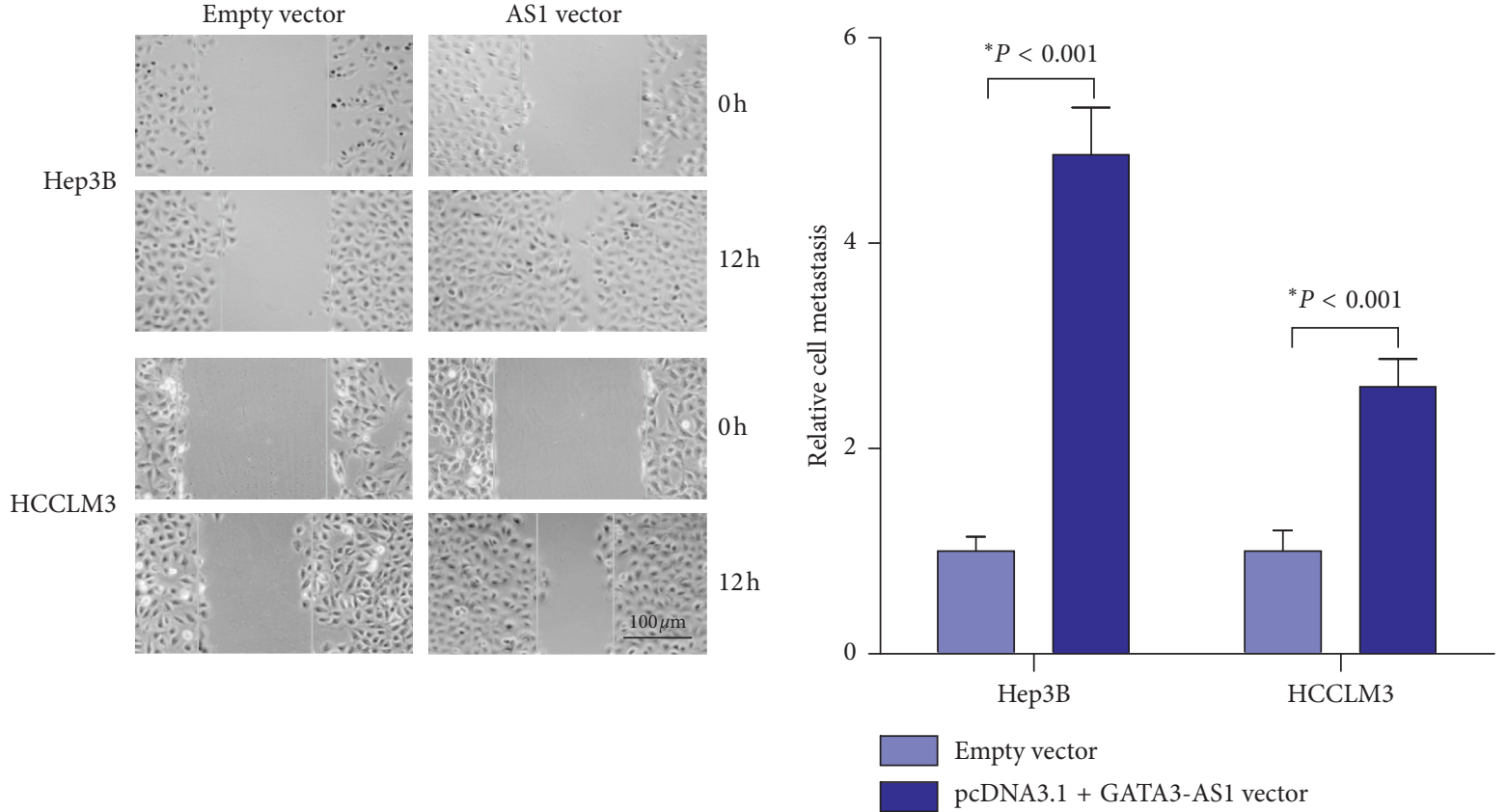

(b)

Figure 5: GATA3-AS1 facilitates cell metastasis in Hep3B and HCCLM3 cells. (a) The wound-healing assay was employed to determine Hep3B and HCCLM3 cell migration after treatment with GATA3-AS1 siRNA/control siRNA. (b) Hep3B and HCCLM3 cells transfected with pcDNA3.1 + GATA3-AS1 vector showed longer distance of cell migration compared with cells transfected with empty vector. Data were expressed as the mean \pm SD $(n=3)$. Bar $=100 \mu \mathrm{m}$ and ${ }^{*} P<0.05$.

TP53 expression. All of these data sufficiently demonstrated that GATA3-AS1 promotes cell proliferation and metastasis in HCC by suppression of PTEN, CDKN1A, and TP53. Some limitations of the study have to be improved in the further research. First, the HCC specimens used in our study are small. Second, how GATA3-AS1 regulates PTEN, CDKN1A, and TP53 remains unclear. Moreover, it is essential to study the role of GATA3-AS1 in more other gastrointestinal cancers in further work, such as gastric cancer, pancreatic cancer, gallbladder cancer, and colorectal cancer.

In conclusion, our results suggested that GATA3-AS1 promotes cell proliferation and metastasis in HCC by 


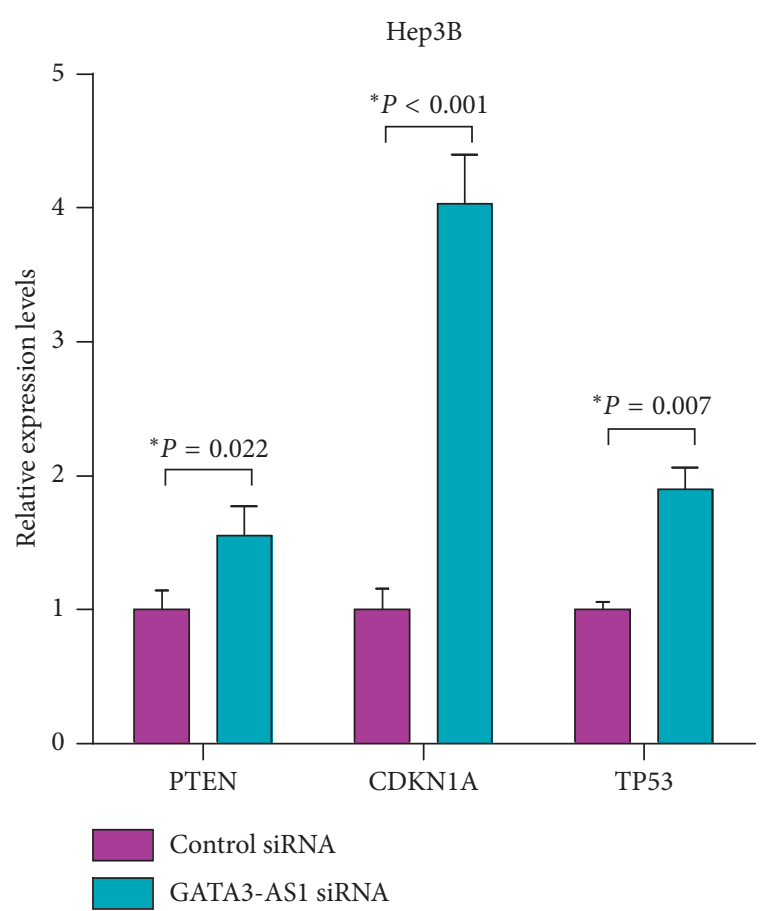

(a)

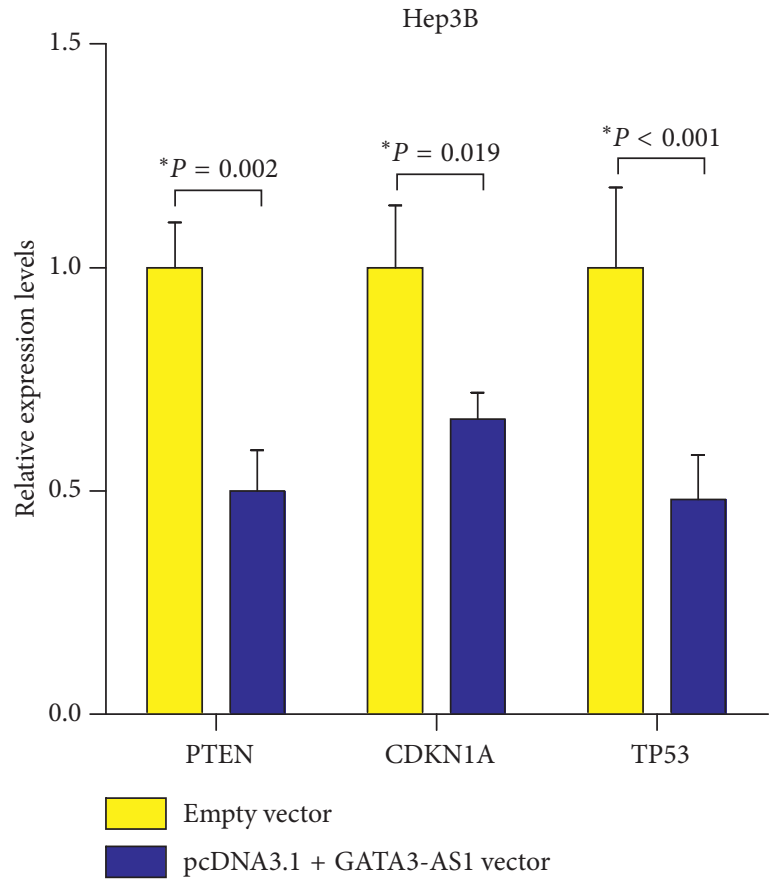

(c)

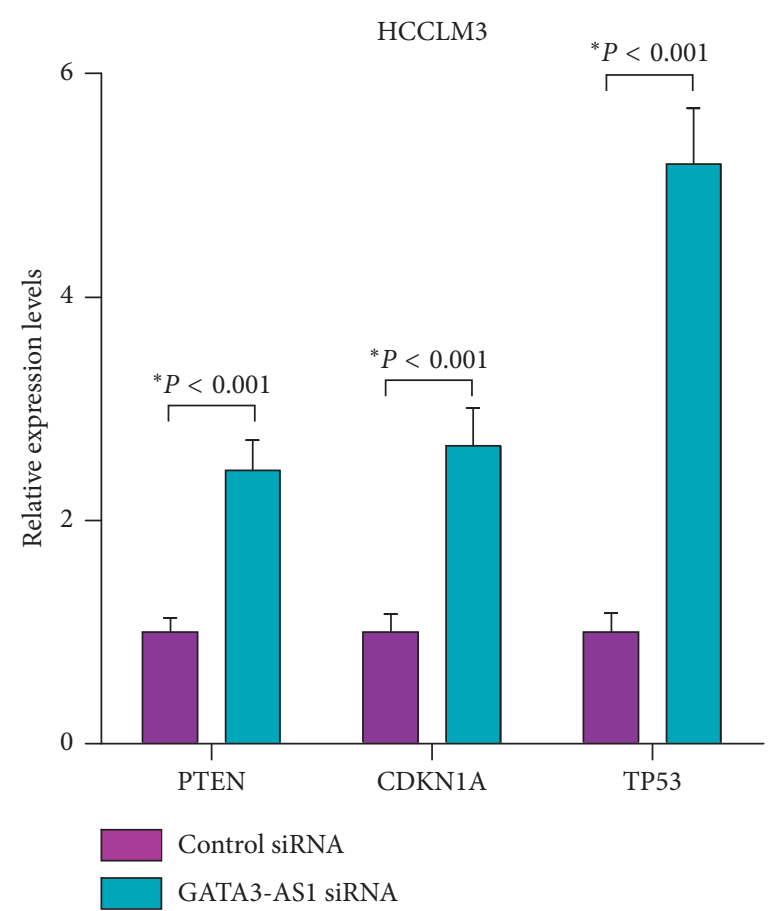

(b)

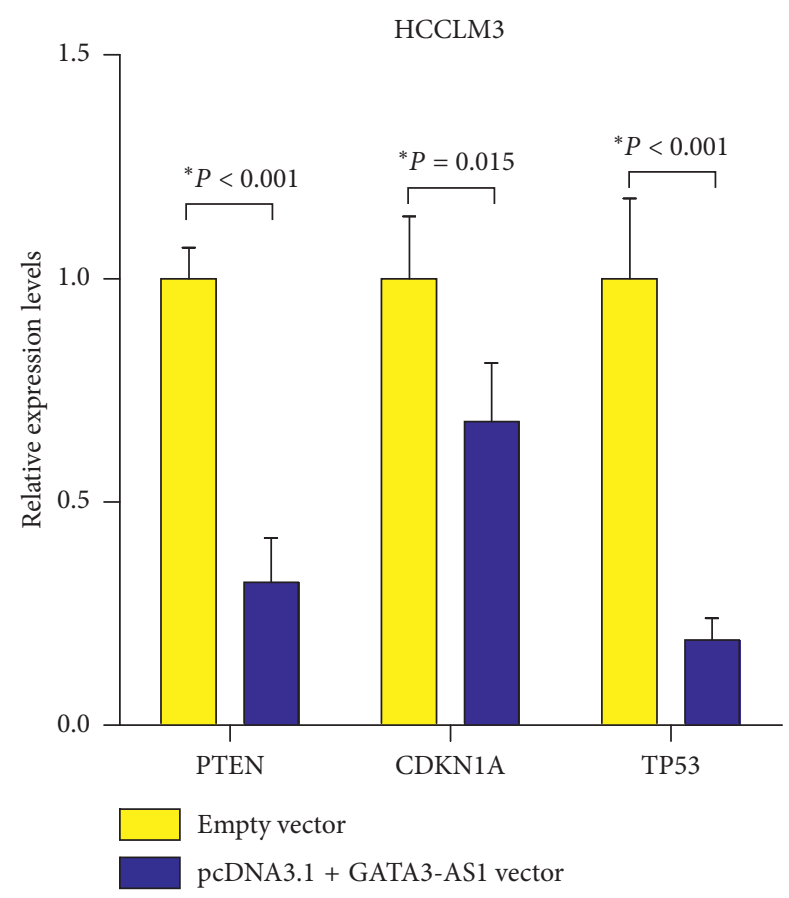

(d)

Figure 6: GATA3-AS1 suppresses PTEN, CDKN1A, and TP53 expression in HCC cells. (a) RT-qPCR analysis was used to detect PTEN, CDKN1A, and TP53 expression in Hep3B and HCCLM3 cells after treated with GATA3-AS1 siRNA/control siRNA. Expression of each gene was normalized to that of the ACTB level. (b) Restoration of GATA3-AS1 decreased PTEN, CDKN1A, and TP53 expression. PTEN: phosphatase and tensin homolog, CDKN1A: cyclin-dependent kinase inhibitor 1A, and TP53: tumor protein p53. Each value represented the mean \pm SD from at least three independent experiments; ${ }^{*} P<0.05$.

suppression of PTEN, CDKN1A, and TP53. Our findings contribute to a better understanding of the importance of GATA3-AS1 in HCC progression and provide a promising lncRNA-based targeted approach for HCC treatment.

\section{Data Availability}

The data used to support the findings of this study are available from the corresponding author upon request. 


\section{Conflicts of Interest}

The authors have not declared any conflicts of interest.

\section{Acknowledgments}

This work was supported by the Hunan Provincial Natural Science Foundation of China (no. 2017JJ3176) and the Youth PhD Fund of Hunan Provincial People's Hospital of China (no. BSJJ201808).

\section{References}

[1] A. Villanueva, "Hepatocellular carcinoma," New England Journal of Medicine, vol. 380, no. 15, pp. 1450-1462, 2019.

[2] L. A. Torre, F. Bray, R. L. Siegel, J. Ferlay, J. Lortet-Tieulent, and A. Jemal, "Global cancer statistics, 2012," CA: A Cancer Journal for Clinicians, vol. 65, no. 2, pp. 87-108, 2015.

[3] M. Ronot, Y. Purcell, and V. Vilgrain, "Hepatocellular carcinoma: current imaging modalities for diagnosis and prognosis," Digestive Diseases and Sciences, vol. 64, no. 4, pp. 934-950, 2019.

[4] L. Kulik and H. B. El-Serag, "Epidemiology and management of hepatocellular carcinoma," Gastroenterology, vol. 156, no. 2, pp. 477-491 e471, 2019.

[5] A. Raza and G. K. Sood, "Hepatocellular carcinoma review: current treatment, and evidence-based medicine," World Journal of Gastroenterology, vol. 20, no. 15, pp. 4115-4127, 2014.

[6] W.-J. Kim and S.-C. Bae, "Molecular biomarkers in urothelial bladder cancer," Cancer Science, vol. 99, no. 4, pp. 646-652, 2008.

[7] T. Gutschner and S. Diederichs, "The hallmarks of cancer: a long non-coding RNA point of view," RNA Biology, vol. 9, no. 6, pp. 703-719, 2012.

[8] L. Ma, V. B. Bajic, and Z. Zhang, "On the classification of long non-coding RNAs,” RNA Biology, vol. 10, no. 6, pp. 925-933, 2013.

[9] V. A. Moran, R. J. Perera, and A. M. Khalil, "Emerging functional and mechanistic paradigms of mammalian long non-coding RNAs," Nucleic Acids Research, vol. 40, no. 14, pp. 6391-6400, 2012.

[10] T. Lan, K. Yuan, X. Yan et al., "LncRNA SNHG10 facilitates hepatocarcinogenesis and metastasis by modulating its homolog SCARNA13 via a positive feedback loop," Cancer Research, vol. 79, no. 13, pp. 3220-3234, 2019.

[11] Y. Wang, L. Yang, T. Chen et al., "A novel lncRNA MCM3APAS1 promotes the growth of hepatocellular carcinoma by targeting miR-194-5p/FOXA1 axis," Molecular Cancer, vol. 18 , no. 1 , p. $28,2019$.

[12] Y. Wang, Y. Dang, J. Liu, and X. Ouyang, "The function of homeobox genes and lncRNAs in cancer," Oncology Letters, vol. 12, no. 3, pp. 1635-1641, 2016.

[13] S.-X. Yuan, Q.-F. Tao, J. Wang et al., "Antisense long noncoding RNA PCNA-AS1 promotes tumor growth by regulating proliferating cell nuclear antigen in hepatocellular carcinoma," Cancer Letters, vol. 349, no. 1, pp. 87-94, 2014.

[14] Y. Xue, G. Ma, Z. Zhang et al., "A novel antisense long noncoding RNA regulates the expression of MDC1 in bladder cancer," Oncotarget, vol. 6, no. 1, pp. 484-493, 2015.

[15] J. He, K. Wu, C. Guo et al., "Long non-coding RNA AFAP1AS1 plays an oncogenic role in promoting cell migration in non-small cell lung cancer," Cellular and Molecular Life Sciences, vol. 75, no. 24, pp. 4667-4681, 2018.
[16] X. Fu, Y. Tian, W. Kuang, S. Wen, and W. Guo, "Long noncoding RNA DLX6-AS1 silencing inhibits malignant phenotypes of gastric cancer cells," Experimental and Therapeutic Medicine, vol. 17, no. 6, pp. 4715-4722, 2019.

[17] G. Hu, Q. Tang, S. Sharma et al., "Expression and regulation of intergenic long noncoding RNAs during T cell development and differentiation," Nature Immunology, vol. 14, no. 11, pp. 1190-1198, 2013.

[18] H. R. Gibbons, G. Shaginurova, L. C. Kim, N. Chapman, C. F. Spurlock III., and T. M. Aune, "Divergent lncRNA GATA3-AS1 regulates GATA3 transcription in T-helper 2 cells," Front Immunol, vol. 9, p. 2512, 2018.

[19] L. Su, T. Zhou, Z. Zhang et al., "Optimal staging system for predicting the prognosis of patients with hepatocellular carcinoma in China: a retrospective study," BMC Cancer, vol. 16, no. 1, p. 424, 2016.

[20] T. D. Schmittgen and K. J. Livak, "Analyzing real-time PCR data by the comparative $\mathrm{C}_{\mathrm{T}}$ method," Nature Protocols, vol. 3, no. 6, pp. 1101-1108, 2008.

[21] J. P. Sfakianos, L. Lin Gellert, A. Maschino et al., "The role of PTEN tumor suppressor pathway staining in carcinoma in situ of the bladder," Urologic Oncology: Seminars and Original Investigations, vol. 32, no. 5, pp. 657-662, 2014.

[22] S. J. Chatterjee, R. Datar, D. Youssefzadeh et al., "Combined effects of p53, p21, and pRb expression in the progression of bladder transitional cell carcinoma," Journal of Clinical Oncology, vol. 22, no. 6, pp. 1007-1013, 2004.

[23] A. M. Puzio-Kuter, M. Castillo-Martin, C. W. Kinkade et al., "Inactivation of p53 and Pten promotes invasive bladder cancer," Genes \& Development, vol. 23, no. 6, pp. 675-680, 2009.

[24] P. Kapranov, A. T. Willingham, and T. R. Gingeras, "Genome-wide transcription and the implications for genomic organization," Nature Reviews Genetics, vol. 8, no. 6, pp. 413-423, 2007.

[25] T. R. Mercer, M. E. Dinger, and J. S. Mattick, "Long noncoding RNAs: insights into functions," Nature Reviews Genetics, vol. 10, no. 3, pp. 155-159, 2009.

[26] P. Li, X. Ruan, L. Yang et al., "A liver-enriched long noncoding RNA, lncLSTR, regulates systemic lipid metabolism in mice," Cell Metabolism, vol. 21, no. 3, pp. 455-467, 2015.

[27] Y. Zhang, Y. Zou, W. Wang et al., "Down-regulated long noncoding RNA MEG3 and its effect on promoting apoptosis and suppressing migration of trophoblast cells," Journal of Cellular Biochemistry, vol. 116, no. 4, pp. 542-550, 2015.

[28] Y. Zhou, R.-G. Fan, C.-L. Qin, J. Jia, X.-D. Wu, and W.-Z. Zha, "LncRNA-H19 activates CDC42/PAK1 pathway to promote cell proliferation, migration and invasion by targeting miR15b in hepatocellular carcinoma," Genomics, vol. 111, no. 6, pp. 1862-1872, 2018.

[29] W. Yu, D. Gius, P. Onyango et al., "Epigenetic silencing of tumour suppressor gene p15 by its antisense RNA," Nature, vol. 451, no. 7175 , pp. 202-206, 2008.

[30] H. Zhang, C. E. Nestor, S. Zhao et al., "Profiling of human $\mathrm{CD}_{4}{ }^{+} \mathrm{T}$-cell subsets identifies the $\mathrm{TH} 2$-specific noncoding RNA GATA3-AS1," Journal of Allergy and Clinical Immunology, vol. 132, no. 4, pp. 1005-1008, 2013.

[31] Y.-P. Zhu, X.-J. Bian, D.-W. Ye et al., "Long noncoding RNA expression signatures of bladder cancer revealed by microarray," Oncology Letters, vol. 7, no. 4, pp. 1197-1202, 2014.

[32] D. Pollutri, L. Gramantieri, L. Bolondi, and F. Fornari, "TP53/ MicroRNA interplay in hepatocellular carcinoma," International Journal of Molecular Sciences, vol. 17, no. 12, p. 2029, 2016. 
[33] L. Chen, L. Luo, W. Chen et al., "MicroRNA-24 increases hepatocellular carcinoma cell metastasis and invasion by targeting p53: miR-24 targeted p53," Biomedicine \& Pharmacotherapy, vol. 84, pp. 1113-1118, 2016.

[34] B. D. Hopkins, B. Fine, N. Steinbach et al., "A secreted PTEN phosphatase that enters cells to alter signaling and survival," Science, vol. 341, no. 6144, pp. 399-402, 2013.

[35] X. Xue, X. Wang, Y. Zhao, R. Hu, and L. Qin, "Exosomal miR93 promotes proliferation and invasion in hepatocellular carcinoma by directly inhibiting TIMP2/TP53INP1/ CDKN1A," Biochemical and Biophysical Research Communications, vol. 502, no. 4, pp. 515-521, 2018. 


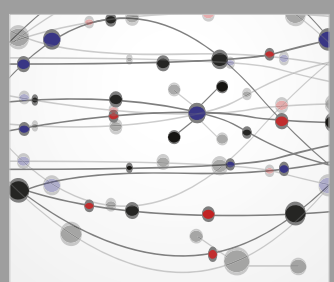

The Scientific World Journal
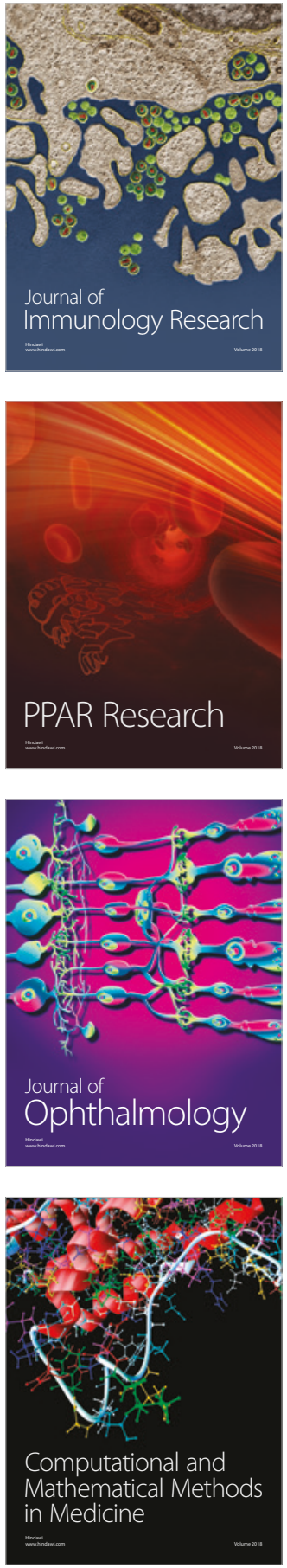

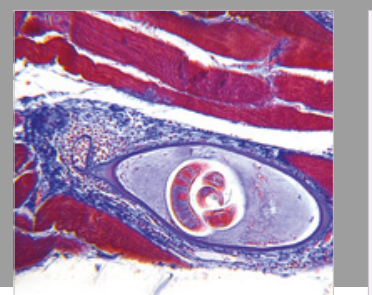

Gastroenterology Research and Practice

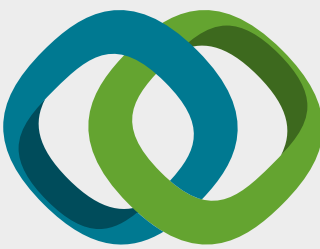

\section{Hindawi}

Submit your manuscripts at

www.hindawi.com
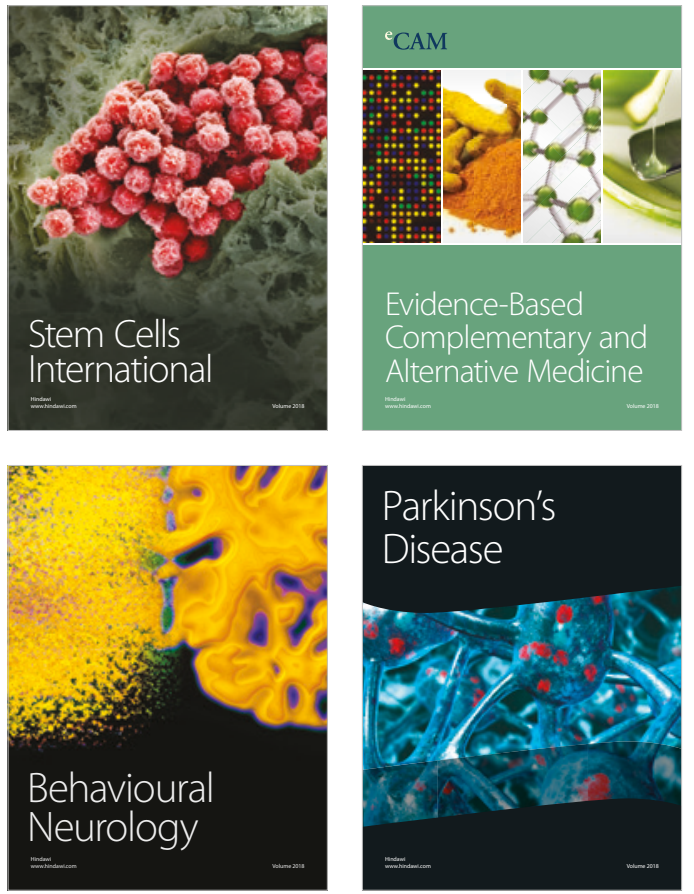

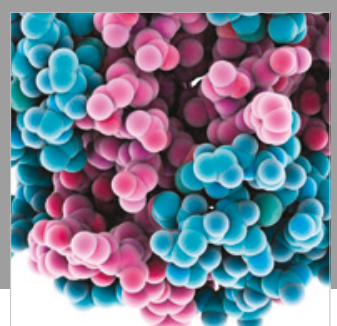

ournal of

Diabetes Research

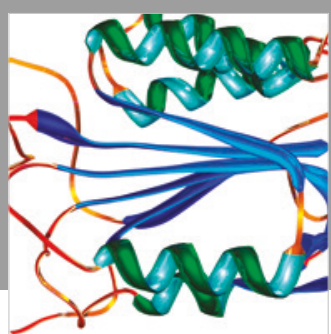

Disease Markers
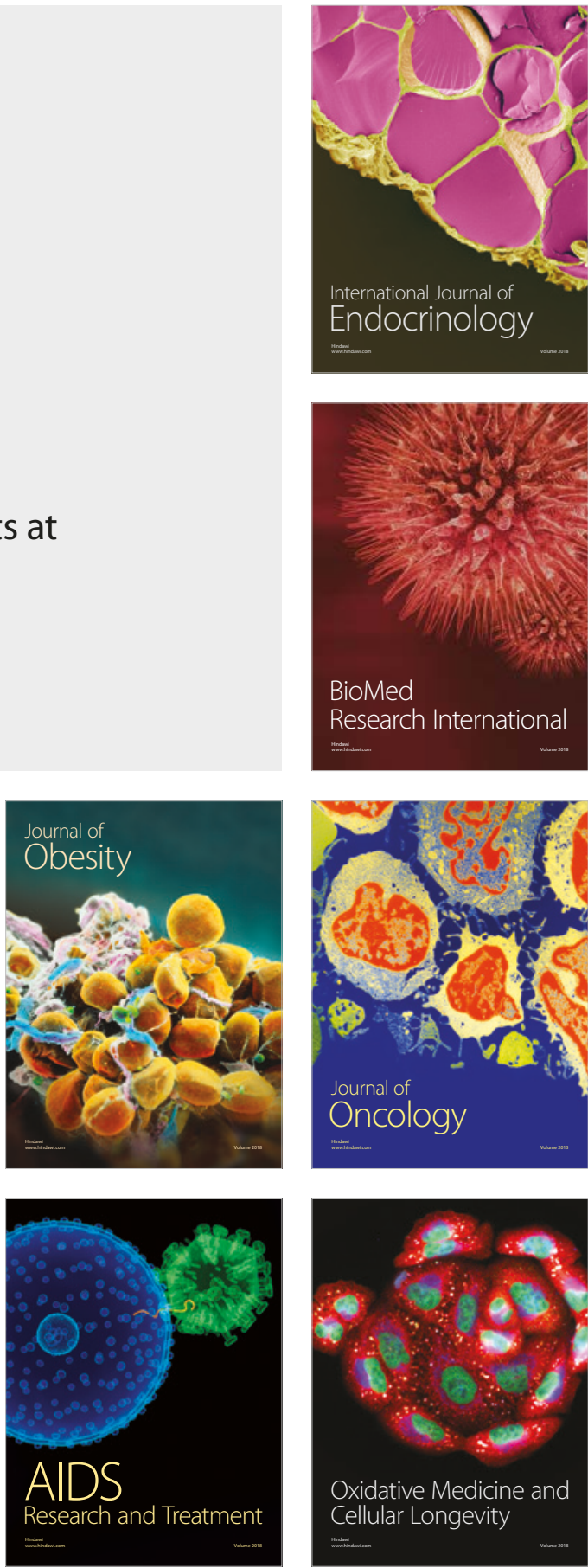